\title{
Interval valued multi criteria decision making methods for the selection of flexible manufactur- ing system
}

\author{
Manoj Mathewa ${ }^{a^{*}}$ and Joji Thomas ${ }^{\mathrm{b}}$
}

${ }^{a}$ Assistant Professor, Department of mechanical engineering, SSIPMT, Raipur, Chhattisgarh, India ${ }^{b}$ Associate Professor, Department of mechanical engineering, CCET, Bhilai, Chhattisgarh, India

\section{CH R O I C LE A B S T RACT}

\section{Article history:}

Received: January 20, 2019

Received in revised format: March 26, 2019

Accepted: April 12, 2019

Available online:

April 12, 2019

Keywords:

Interval-valued TOPSIS

Interval-valued EDAS

Interval-valued CODAS

FMS selection

$M C D M$

\begin{abstract}
In real world multi criteria decision making (MCDM) problem, it is tough to solve a decision matrix with vague and imprecise data. The degree of impreciseness depends on the kind of data available. For interval valued data this impreciseness is less and interval-valued MCDM methods can be effectively used to solve the problem. A flexible manufacturing system (FMS) selection problem was taken into consideration to find the best FMS among available alternatives. An interval extension of CODAS method is proposed in this paper which was used to solve the problem along with two other interval-valued decision-making methods i.e. interval-valued TOPSIS, interval-valued EDAS. All the three methods are distance-based approaches and it was found that the interval-valued CODAS method gave the exact same ranking with that of interval-valued TOPSIS and interval-valued EDAS.
\end{abstract}

\section{Introduction}

Flexible-manufacturing system (FMS) is a system which integrates programmable devices, equipment and machines with a computer for manufacturing an extensive range of products. There are various conflicting criteria like costs, efficiency, flexibility, etc. on which the selection of FMS depends. Hence Multi Criteria Decision Making (MCDM) methods play a crucial role in the selection of best FMS among available alternative. Generally, the decision matrix in MCDM problem consist of crisp numeric values (ordinary data), but in practical there are many instances where it's tough to get these crisp numeric values. Instead of ordinary data the values can be fuzzy data or interval data. These fuzzy or interval valued data are imprecise in nature and cannot be used for direct calculations using conventional MCDM methods. So, these data are either converted into crisp score or modified formula are used to solve the problem. Researchers have created and extended many conventional MCDM methods to interval-valued 
MCDM methods which were used to solve interval valued MCDM problem. (Pan, et al., 2000) used linear additive utility function and composite utility variance to solve interval valued MCDM problem. (Sayadi, et al., 2009) extended the VIKOR method to formulate interval-valued VIKOR method. (Chen, et al., 2010) considered loss aversion to form a method which could be used to solve interval- valued MCDM problem. (Sayyadi \& Makui, 2012) extended ELECTRE method to create interval valued ELECTRE. (Stanujkic, et al., 2014) extended MOORA method for interval data to select a grinding circuit. (Kracka \& Zavadskas, 2013) extended MULTIMOORA method to create interval MULTIMOORA for the selection of structural panels. (Hafezalkotob \& Hafezalkotob, 2017) extended the MULTIMOORA method and formulated interval MULTIMOORA method which used interval preference matrix, they used it for the selection of bio materials. They have also extended VIKOR method using interval algorithm and different normalization technique (Hafezalkotob \& Hafezalkotob, 2017). There are many more interval valued MCDM methods which are discussed below.

\section{Interval-valued TOPSIS}

Technique for Order of Preference by Similarity to Ideal Solution (TOPSIS) is a famous classical multi criteria decision making method which is based on the concept that the best alternative should have the shortest Euclidean distance from the ideal solution. This method was developed by Hwang and Yoon in the year 1981. Classical TOPSIS method was used to solve MCDM problem with crisp numeric value. (Jahanshahloo, et al., 2006), (Jahanshahloo, et al., 2009), (Jahanshahloo, et al., 2011) developed interval extension of TOPSIS, an algorithm which could be used to solve MCDM problem containing interval data. (Ye \& Li, 2009) proposed two group decision making TOPSIS model based on deviation degree and risk factor. (Tsaur, 2011) gave a normalised TOPSIS method for interval valued data which was achieved using different risk attitudes. (Dymova, et al., 2013) proposed an approach which is direct extension of interval valued TOPSIS which uses interval data for calculating the ideal solutions. The algorithm for solving MCDM problem with interval data using TOPSIS consists of following steps:

Consider a decision matrix with interval valued data $\left[\left[\mathrm{X}_{\mathrm{ij}}^{\mathrm{l}}, \mathrm{X}_{\mathrm{ij}}^{\mathrm{u}}\right]\right]_{\mathrm{mn}}$ having ' $\mathrm{m}$ ' alternative and ' $\mathrm{n}$ ' criterion, where $\mathrm{W}_{\mathrm{j}}$ is the weights of the criterion and $\sum_{\mathrm{j}=1}^{\mathrm{n}} \mathrm{W}_{\mathrm{j}}=1$. The value of $i \in\{1,2, \ldots, \mathrm{m}\}$ and $j \in\{1,2, \ldots, \mathrm{n}\}$.

Step1: - Calculate the normalised interval valued decision matrix $\left[\mathrm{N}_{\mathrm{ij}}^{\mathrm{l}}, \mathrm{N}_{\mathrm{ij}}^{\mathrm{u}}\right]$

Where $\mathrm{N}_{\mathrm{ij}}^{\mathrm{l}}=\frac{\mathrm{x}_{\mathrm{ij}}^{\mathrm{l}}}{\left(\sum_{\mathrm{i}=1}^{\mathrm{m}}\left(\left(\mathrm{x}_{\mathrm{ij}}^{\mathrm{l}}\right)^{2}+\left(\mathrm{x}_{\mathrm{ij}}^{\mathrm{u}}\right)^{2}\right)\right)^{0.5}}$ and $\mathrm{N}_{\mathrm{ij}}^{\mathrm{u}}=\frac{\mathrm{x}_{\mathrm{ij}}^{\mathrm{u}}}{\left(\sum_{\mathrm{i}=1}^{\mathrm{m}}\left(\left(\mathrm{x}_{\mathrm{ij}}^{\mathrm{l}}\right)^{2}+\left(\mathrm{x}_{\mathrm{ij}}^{\mathrm{u}}\right)^{2}\right)\right)^{0.5}}$

Step2: - Calculate the weighted normalised interval valued decision matrix $\left[v_{\mathrm{ij}}^{\mathrm{l}}, \mathrm{v}_{\mathrm{ij}}^{\mathrm{u}}\right]$

Where $v_{\mathrm{ij}}^{\mathrm{l}}=\mathrm{W}_{\mathrm{j}} \mathrm{N}_{\mathrm{ij}}^{\mathrm{l}}$ and $\mathrm{u}_{\mathrm{ij}}^{\mathrm{u}}=\mathrm{W}_{\mathrm{j}} \mathrm{N}_{\mathrm{ij}}^{\mathrm{u}}$

Step3: - Calculate the positive and negative ideal solutions

Let Alternative $A_{k}$ be defined as the ideal solution. Then G. R. Jahanshahloo et al. (Jahanshahloo, et al., 2009), (Jahanshahloo, et al., 2011) defined it as

$\mathrm{A}^{+}=\left\{\left(\mathrm{v}_{1}^{+}, \mathrm{v}_{2}^{+}, \ldots, \mathrm{v}_{\mathrm{n}}^{+}\right)\right\}=\left\{\left(\max _{\mathrm{i}} \mathrm{v}_{\mathrm{ij}}^{u} \mid \mathrm{j} \in \mathrm{B}\right),\left(\min _{\mathrm{i}} \mathrm{v}_{\mathrm{ij}}^{l} \mid \mathrm{j} \in \mathrm{N}\right)\right\}$

$A^{-}=\left\{\left(v_{1}^{-}, v_{2}^{-}, \ldots, v_{n}^{-}\right)\right\}=\left\{\left(\min _{i} v_{i j}^{l} \mid j \in B\right),\left(\max _{i} v_{i j}^{u} \mid j \in N\right)\right\}$

Where $\mathrm{B}$ is associated with beneficial criteria and $\mathrm{N}$ is associated with non-beneficial criteria.

(Dymova, et al., 2013) gave an interval form for calculating ideal solutions, which is shown below

$A^{+}=\left\{\left[v_{1}^{+1}, v_{1}^{+u}\right],\left[v_{2}^{+1}, v_{2}^{+u}\right], \ldots,\left[v_{n}^{+1}, v_{n}^{+u}\right]\right\}=\left\{\left(\max _{\mathrm{i}}\left\{v_{\mathrm{ij}}^{l}, v_{\mathrm{ij}}^{u}\right\} \mid j \in B\right),\left(\min _{\mathrm{i}}\left\{\mathrm{v}_{\mathrm{ij}}^{\mathrm{l}}, \mathrm{v}_{\mathrm{ij}}^{\mathrm{u}}\right\} \mid \mathrm{j} \in \mathrm{N}\right)\right\}$

$A^{-}=\left\{\left[v_{1}^{-1}, v_{1}^{+u}\right],\left[v_{2}^{+1}, v_{2}^{+u}\right], \ldots,\left[v_{n}^{+1}, v_{n}^{+u}\right]\right\}=\left\{\left(\min _{i}\left\{v_{i j}^{l}, v_{i j}^{u}\right\} \mid j \in B\right),\left(\max _{i}\left\{v_{i j}^{l}, v_{i j}^{u}\right\} \mid j \in N\right)\right\}$

For comparing two interval valued data $\Delta_{A-B}=\left(0.5\left(a^{l}+a^{u}\right)-0.5\left(b^{u}+b^{l}\right)\right)$ formula can be used. If the value of $\Delta_{A-B}$ is negative then $\mathrm{A} \leq \mathrm{B}$ and if the value of $\Delta_{A-B}$ is positive then $\mathrm{A} \geq \mathrm{B}$.

Step4: - Calculate the separation measure of each alternative

(Jahanshahloo, et al., 2011) calculated the separation measures of each alternative from the positive and negative ideal solution using the Euclidean distance, which is shown below 


$$
\begin{aligned}
& \mathrm{S}_{i}^{+}=\sqrt{\sum_{j \in B}\left(\mathrm{v}_{\mathrm{ij}}^{l}-\mathrm{v}_{\mathrm{j}}^{+}\right)^{2}+\sum_{j \in N}\left(\mathrm{v}_{\mathrm{ij}}^{u}-\mathrm{v}_{\mathrm{j}}^{+}\right)^{2}} \\
& \mathrm{~S}_{i}^{-}=\sqrt{\sum_{j \in B}\left(\mathrm{v}_{\mathrm{ij}}^{u}-\mathrm{v}_{\mathrm{j}}^{-}\right)^{2}+\sum_{j \in N}\left(\mathrm{v}_{\mathrm{ij}}^{l}-\mathrm{v}_{\mathrm{j}}^{-}\right)^{2}}
\end{aligned}
$$

(Dymova, et al., 2013) gave a new formula for calculating separation measures which is not based on Euclidean distance, which is shown below

$$
\begin{aligned}
& \mathrm{S}_{\mathrm{i}}^{+}=\frac{1}{2} \sum_{j \in B}\left(\left(v_{\mathrm{j}}^{+l}+\mathrm{v}_{\mathrm{j}}^{+u}\right)-\left(\mathrm{v}_{\mathrm{ij}}^{l}+\mathrm{v}_{\mathrm{ij}}^{u}\right)\right)+\frac{1}{2} \sum_{j \in N}\left(\left(v_{\mathrm{ij}}^{l}+\mathrm{v}_{\mathrm{ij}}^{u}\right)-\left(\mathrm{v}_{\mathrm{j}}^{+l}+\mathrm{v}_{\mathrm{j}}^{+u}\right)\right) \\
& \mathrm{S}_{\mathrm{i}}^{-}=\frac{1}{2} \sum_{j \in B}\left(\left(v_{\mathrm{ij}}^{l}+\mathrm{v}_{\mathrm{ij}}^{u}\right)-\left(\mathrm{v}_{\mathrm{j}}^{-l}+\mathrm{v}_{\mathrm{j}}^{-u}\right)\right)+\frac{1}{2} \sum_{j \in N}\left(\left(v_{\mathrm{j}}^{-l}+\mathrm{v}_{\mathrm{j}}^{-u}\right)-\left(\mathrm{v}_{\mathrm{ij}}^{l}+\mathrm{v}_{\mathrm{ij}}^{u}\right)\right)
\end{aligned}
$$

Step5: - Calculate the relative closeness to the ideal solution

$\mathrm{R}_{\mathrm{i}}=\frac{\mathrm{S}_{\mathrm{i}}^{-}}{\mathrm{S}_{\mathrm{i}}^{-}+\mathrm{S}_{\mathrm{i}}^{+}}$where $i \in\{1,2, \ldots, \mathrm{m}\}$ and $0 \leq \mathrm{R}_{\mathrm{i}} \leq 1$

Step6: - Rank the alternative based on $R_{i}$ value, the alternative $A_{i}$ with highest $R_{i}$ value will be ranked 1 while the alternative $A_{i}$ with lowest $R_{i}$ value will be the last ranked alternative.

\section{Interval-valued EDAS}

The Evaluation Based on Distance from Average Solution (EDAS) method was proposed by (Keshavarz Ghorabaee, et al., 2015). EDAS is a distance-based approach in which the best alternative should have higher distance from positive distance from Average (PDA) and lesser distance from the Negative Distance from Average (NDA) (Mathew \& Sahu, 2018). (Stanujkic, et al., 2017) proposed the extension of EDAS method, which can be used in interval grey number. The same extension of EDAS method can be used for solving interval valued MCDM problem. The algorithm for solving interval valued MCDM problem using interval valued EDAS consists of following steps:

Consider a decision matrix with interval valued data $\left[\left[\mathrm{X}_{\mathrm{ij}}^{\mathrm{l}}, \mathrm{X}_{\mathrm{ij}}^{\mathrm{u}}\right]\right]_{\mathrm{mn}}$ having ' $\mathrm{m}$ ' alternative and ' $\mathrm{n}$ ' criterion, where $\mathrm{W}_{\mathrm{j}}$ is the weights of the criterion and $\sum_{\mathrm{j}=1}^{\mathrm{n}} \mathrm{W}_{\mathrm{j}}=1$. The value of $i \in\{1,2, \ldots, \mathrm{m}\}$ and $j \in\{1,2, \ldots, \mathrm{n}\}$.

Step1: - Calculate the interval valued average solution $\left[A_{j}^{1}, A_{j}^{u}\right]$

$\left[A_{j}^{l}, A_{j}^{u}\right]=\left(\left[A_{1}^{l}, A_{1}^{u}\right],\left[A_{2}^{l}, A_{2}^{u}\right], \ldots,\left[A_{n}^{l}, A_{n}^{u}\right]\right)$

where $A_{\mathrm{j}}^{\mathrm{l}}=\frac{\sum_{i=1}^{m} \mathrm{X}_{\mathrm{ij}}^{\mathrm{l}}}{m}$ and $\mathrm{A}_{\mathrm{j}}^{u}=\frac{\sum_{i=1}^{m} \mathrm{X}_{\mathrm{ij}}^{\mathrm{u}}}{m}$

Step2: - Calculate the interval valued PDA $\left[D_{i j}^{+1}, D_{i j}^{+u}\right]$ and interval valued NDA $\left[D_{i j}^{-1}, D_{i j}^{-u}\right]$

$$
D_{i j}^{+l}=\left\{\begin{array}{l}
\frac{\max \left(0,\left(X_{i j}^{l}-A_{j}^{u}\right)\right)}{0.5\left(A_{j}^{l}+A_{j}^{u}\right)} ; j \in B \\
\frac{\max \left(0,\left(A_{j}^{l}-X_{i j}^{u}\right)\right)}{0.5\left(A_{j}^{l}+A_{j}^{u}\right)} ; j \in N
\end{array}, D_{i j}^{+u}=\left\{\begin{array}{l}
\frac{\max \left(0,\left(X_{i j}^{u}-A_{j}^{l}\right)\right)}{0.5\left(A_{j}^{l}+A_{j}^{u}\right)} ; j \in B \\
\frac{\max \left(0,\left(A_{j}^{u}-X_{i j}^{l}\right)\right)}{0.5\left(A_{j}^{l}+A_{j}^{u}\right)} ; j \in N
\end{array}\right.\right.
$$




$$
D_{i j}^{-1}=\left\{\begin{array}{l}
\frac{\max \left(0,\left(A_{j}^{l}-X_{i j}^{u}\right)\right)}{0.5\left(A_{j}^{l}+A_{j}^{u}\right)} ; j \in B \\
\frac{\max \left(0,\left(X_{i j}^{l}-A_{j}^{u}\right)\right)}{0.5\left(A_{j}^{l}+A_{j}^{u}\right)} ; j \in N
\end{array}, D_{i j}^{-u}=\left\{\begin{array}{l}
\frac{\max \left(0,\left(A_{j}^{u}-X_{i j}^{l}\right)\right)}{0.5\left(A_{j}^{l}+A_{j}^{u}\right)} ; j \in B \\
\frac{\max \left(0,\left(X_{i j}^{u}-A_{j}^{l}\right)\right)}{0.5\left(A_{j}^{l}+A_{j}^{u}\right)} ; j \in N
\end{array}\right.\right.
$$

where $\mathrm{B}$ is associated with beneficial criteria and $\mathrm{N}$ is associated with non-beneficial or cost criteria.

Step3: - Calculate the weighted sum of interval valued PDA $\left[\mathrm{Q}_{\mathrm{i}}^{+1}, \mathrm{Q}_{\mathrm{i}}^{+\mathrm{u}}\right]$ and interval valued NDA $\left[\mathrm{Q}_{\mathrm{i}}^{-\mathrm{l}}, \mathrm{Q}_{\mathrm{i}}^{-\mathrm{u}}\right]$.

$\begin{array}{ll}\mathrm{Q}_{\mathrm{i}}^{+\mathrm{l}}=\sum_{j=1}^{n} W_{j} \mathrm{D}_{\mathrm{ij}}^{+\mathrm{l}} & , \mathrm{Q}_{\mathrm{i}}^{+\mathrm{u}}=\sum_{j=1}^{n} W_{j} \mathrm{D}_{\mathrm{ij}}^{+\mathrm{u}} \\ \mathrm{Q}_{\mathrm{i}}^{-\mathrm{l}}=\sum_{j=1}^{n} W_{j} \mathrm{D}_{\mathrm{ij}}^{-\mathrm{l}} & , \mathrm{Q}_{\mathrm{i}}^{-\mathrm{u}}=\sum_{j=1}^{n} W_{j} \mathrm{D}_{\mathrm{ij}}^{-\mathrm{u}}\end{array}$

Step4: - Calculate the normalised value of $\left[\mathrm{Q}_{\mathrm{i}}^{+1}, \mathrm{Q}_{\mathrm{i}}^{+\mathrm{u}}\right]$ and $\left[\mathrm{Q}_{\mathrm{i}}^{-1}, \mathrm{Q}_{\mathrm{i}}^{-\mathrm{u}}\right]$

$\mathrm{S}_{\mathrm{i}}^{+1}=\frac{\mathrm{Q}_{\mathrm{i}}^{+1}}{\max _{k} \mathrm{Q}_{\mathrm{k}}^{+\mathrm{u}}}, \mathrm{S}_{\mathrm{i}}^{+\mathrm{u}}=\frac{\mathrm{Q}_{\mathrm{i}}^{+\mathrm{u}}}{\max _{k} \mathrm{Q}_{\mathrm{k}}^{+\mathrm{u}}}$

$\mathrm{S}_{\mathrm{i}}^{-1}=1-\frac{\mathrm{Q}_{\mathrm{i}}^{-\mathrm{u}}}{\max _{k} \mathrm{Q}_{\mathrm{k}}^{+\mathrm{u}}}, \mathrm{S}_{\mathrm{i}}^{-\mathrm{u}}=1-\frac{\mathrm{Q}_{\mathrm{i}}^{-\mathrm{l}}}{\max _{k} \mathrm{Q}_{\mathrm{k}}^{+\mathrm{u}}}$

Step5: - Calculate the appraisal score $S_{\mathrm{i}}$ for the alternatives.

$\mathrm{S}_{\mathrm{i}}=\frac{1}{2}\left((1-\propto)\left(\mathrm{S}_{\mathrm{i}}^{+1}+\mathrm{S}_{\mathrm{i}}^{-1}\right)+\propto\left(\mathrm{S}_{\mathrm{i}}^{+\mathrm{u}}+\mathrm{S}_{\mathrm{i}}^{-\mathrm{u}}\right)\right)$

$S_{i}=\frac{1}{4}\left(S_{i}^{+1}+S_{i}^{-1}+S_{i}^{+u}+S_{i}^{-u}\right)$ for $\propto=0.5$ when given equal importance to both lower and upper bounds of interval value.

Step6: - Rank the alternative based on $S_{i}$ value, the alternative $A_{i}$ with highest $S_{i}$ value will be ranked 1 while the alternative $A_{i}$ with lowest $S_{i}$ value will be the last ranked alternative.

\section{Interval Valued CODAS}

Combinative Distance-based Assessment (CODAS) method was developed by (Keshavarz Ghorabaee, et al., 2016) CODAS method is also a distance-based approach which uses Euclidean and Taxicab distances to find the best alternative. An interval extension of CODAS method is proposed in this paper, which uses the same concepts with that of CODAS. The algorithm of interval-valued CODAS is shown below. Consider a decision matrix with interval valued data $\left[\left[X_{i j}^{l}, X_{i j}^{u}\right]\right]_{m n}$ having ' $m$ ' alternative and ' $n$ ' criterion, where $W_{j}$ is the weights of the criterion and $\sum_{j=1}^{n} W_{j}=1$. The value of $i \in\{1,2, \ldots, m\}$ and $j \in\{1,2, \ldots, \mathrm{n}\}$.

Step-1 Calculate the normalized interval valued decision matrix $\left[\mathrm{N}_{\mathrm{ij}}^{1}, \mathrm{~N}_{\mathrm{ij}}^{\mathrm{u}}\right]$

$$
\text { Where } N_{\mathrm{ij}}^{1}=\frac{\mathrm{X}_{\mathrm{ij}}^{\mathrm{l}}}{\max _{i} \mathrm{X}_{\mathrm{ij}}^{\mathrm{u}}} \text { and } N_{\mathrm{ij}}^{\mathrm{u}}=\frac{\mathrm{X}_{\mathrm{ij}}^{\mathrm{u}}}{\max _{i} \mathrm{X}_{\mathrm{ij}}^{\mathrm{u}}} ; j \in \mathrm{B}
$$

$\mathrm{N}_{\mathrm{ij}}^{\mathrm{l}}=\frac{\min _{i} \mathrm{X}_{\mathrm{ij}}^{\mathrm{l}}}{\mathrm{X}_{\mathrm{ij}}^{\mathrm{u}}}$ and $\mathrm{N}_{\mathrm{ij}}^{\mathrm{u}}=\frac{\min _{i} \mathrm{X}_{\mathrm{ij}}^{\mathrm{l}}}{\mathrm{X}_{\mathrm{ij}}^{l}} ; \mathrm{j} \in \mathrm{N}$

where $\mathrm{B}$ is associated with beneficial criteria and $\mathrm{N}$ is associated with non-beneficial or cost criteria. 
Step-2 Calculate the weighted normalized interval valued decision matrix $\left[\mathrm{r}_{\mathrm{ij}}^{\mathrm{l}}, r_{\mathrm{ij}}^{\mathrm{u}}\right]$ where $\mathrm{r}_{\mathrm{ij}}^{\mathrm{l}}=\mathrm{W}_{\mathrm{j}} \mathrm{N}_{\mathrm{ij}}^{\mathrm{l}}$ and $r_{\mathrm{ij}}^{\mathrm{u}}=\mathrm{W}_{\mathrm{j}} \mathrm{N}_{\mathrm{ij}}^{\mathrm{u}}$

Step-3 Determine the interval valued negative-ideal solution

For comparing two interval valued data $\Delta_{A-B}=\left(0.5\left(a^{l}+a^{u}\right)-0.5\left(b^{u}+b^{l}\right)\right)$ formula can be used. If the value of $\Delta_{A-B}$ is negative then $\mathrm{A} \leq \mathrm{B}$ and if the value of $\Delta_{A-B}$ is positive then $\mathrm{A} \geq \mathrm{B}$.

$\mathrm{NS}_{\mathrm{j}}=\left\{\left[\mathrm{r}_{1}^{-1}, r_{1}^{-\mathrm{u}}\right],\left[r_{2}^{-\mathrm{l}}, r_{2}^{-\mathrm{u}}\right], \ldots,\left[\mathrm{r}_{\mathrm{n}}^{-\mathrm{l}}, \mathrm{r}_{\mathrm{n}}^{-\mathrm{u}}\right]\right\}=\min _{i}\left\{\mathrm{v}_{\mathrm{ij}}^{\mathrm{l}}, \mathrm{v}_{\mathrm{ij}}^{\mathrm{u}}\right\}$

Step-4 Calculate the Euclidean $\left(\mathrm{E}_{\mathrm{i}}\right)$ and Taxicab $\left(T_{\mathrm{i}}\right)$ distances of alternatives from the interval valued negative-ideal solution

$\mathrm{E}_{\mathrm{i}}=\sqrt{\sum\left(\mathrm{r}_{\mathrm{ij}}^{l}-r_{\mathrm{j}}^{-l}\right)^{2}+\sum\left(\mathrm{r}_{\mathrm{ij}}^{u}-\mathrm{r}_{\mathrm{j}}^{-l}\right)^{2}}$

$T_{\mathrm{i}}=\sum\left|\mathrm{r}_{\mathrm{ij}}^{l}-r_{\mathrm{j}}^{-l}\right|+\sum\left|\mathrm{r}_{\mathrm{ij}}^{u}-r_{\mathrm{j}}^{-l}\right|$

Step-5 Formulating the relative assessment matrix

The relative assessment matrix $R_{a}$ is obtained by

$$
\begin{aligned}
& R_{a}=\left[h_{i k}\right]_{m \times \mathrm{m}} \\
& h_{i k}=\left(E_{i}-E_{k}\right)+\left(\psi\left(E_{i}-E_{k}\right) \times\left(T_{i}-T_{k}\right)\right.
\end{aligned}
$$

where $k \in\{1,2, \ldots, \mathrm{m}\}$ and $\psi$ denotes a threshold function to recognize the equality of the Euclidean distances of two alternatives which is defined as

$\psi(x)= \begin{cases}1, & \text { if }|x| \geq \tau \\ 0, & \text { if }|x|<\tau\end{cases}$

$\tau$ is the threshold parameter which is set as 0.01 for this paper. It is suggested that $0.01<\tau<0.05$.

Step-6 Calculate the final assessment score of each alternative

$H_{i}=\sum_{k=1}^{m} h_{i k}$

The alternative having highest $H_{i}$ value is the best choice among the alternatives.

\section{Example}

Kulak and Kahraman (2005) solved a decision-making problem in which a tractors component manufacturing company wanted to select the best FMS among different FMSs alternative. The FMS alternatives were selected on the basis of 6 criteria i.e. annual depreciation and maintenance costs (ADM) which is a non-beneficial criterion, quality of results $(\mathrm{Q})$, ease of use (E), competitiveness $(C)$, adaptability (A) and expandability $(\mathrm{X})$ are beneficial criteria. The minimum and maximum values of the criteria for different alternative is shown in the Table 1. Kulak and Kahraman (2005) converted the interval valued decision matrix into decision matrix with linguistic terms, which was solved using fuzzy multi attribute axiomatic design approach to select the best FMS. Rao and Parnichkun (2009) solved the same problem having linguistic terms in the decision matrix using combinatorial mathematics-based decision-making method and also calculated the weights of the criteria using Analytic Hierarchy Process. In the present work, same criteria weights were considered for solving interval valued decision matrix. The weights are: $W_{A D M}=0.4188, W_{Q}=0.1875, W_{E}=0.0688, W_{C}=0.1873, W_{A}=0.0688, W_{X}=0.0688$. Rao and Singh (2011) used Euclidean distance-based integrated approach (EDBA) to solve the same problem having linguistic terms in the decision matrix. Maniya and Bhatt (2011) solved the same problem using preference selection index method. Karande and Chakraborty (2013) used MACBETH software to select the best FMS. In the present work instead of using linguistic termed decision matrix, which was further converted to 
crisp value using seven point fuzzy scale (Rao \& Singh, 2011) or 11 point conversion scale (Rao \& Parnichkun, 2009), (Maniya \& Bhatt, 2011), Interval data decision matrix was used to find the best FMS, which is shown in Table 1. In the decision matrix, performance value of FMS-1 and FMS-2 for adaptability(criterion) is 12-18 and 15-17 respectively, which was converted using triangular fuzzy Number (TFN) by Kulak and Kahraman (2005) and was allotted the same TFN i.e. very good. These TFN when further converted to crisp value seven point fuzzy scale (Rao \& Singh, 2011) or 11 point conversion scale (Rao \& Parnichkun, 2009), (Maniya \& Bhatt, 2011) gives same crisp value, so to get more accurate results Interval data decision matrix was solved using interval-valued TOPSIS and interval-valued EDAS in this paper.

Table 1

Interval data decision matrix for the selection of FMS

\begin{tabular}{ccccccc}
\hline & ADM $(\mathrm{X} \$ 1000)$ & $\mathrm{Q}$ & $\mathrm{E}$ & $\mathrm{C}$ & $\mathrm{A}$ & $\mathrm{X}$ \\
\hline FMS-1 & $210-240$ & $18-20$ & $13-20$ & $16-20$ & $12-18$ & $12-16$ \\
FMS-2 & $80-120$ & $12-17$ & $9-14$ & $12-17$ & $15-17$ & $14-18$ \\
FMS-3 & $180-220$ & $8-12$ & $10-14$ & $13-18$ & $19-20$ & $9-14$ \\
FMS-4 & $140-170$ & $7-10$ & $8-14$ & $13-17$ & $12-16$ & $11-13$ \\
\hline
\end{tabular}

Source: Kulak and Kahraman (2005)

\subsection{Interval-valued TOPSIS}

This interval valued decision matrix was solved using interval valued TOPSIS. The interval valued decision matrix was normalised and weighted normalised interval valued decision matrix was calculated along with positive and negative ideal solutions proposed by (Dymova, et al., 2013), which is shown in Table 2. The separation measures of each alternative from the positive and negative ideal solutions was calculated and finally relative closeness to the idea solution was calculated to find the final raking of alternatives, which is shown in table-3

Table 2

Weighted normalised interval valued decision matrix

\begin{tabular}{rllllll}
\hline & ADM & Q & E & C & A & X \\
\hline FMS-1 & {$[0.1753,0.2003]$} & {$[0.0867,0.0964]$} & {$[0.0239,0.0367]$} & {$[0.0664,0.0829]$} & {$[0.0178,0.0268]$} & {$[0.0214,0.0285]$} \\
FMS-2 & {$[0.0668,0.1002]$} & {$[0.0578,0.0819]$} & {$[0.0165,0.0257]$} & {$[0.0498,0.0705]$} & {$[0.0223,0.0253]$} & {$[0.0250,0.0321]$} \\
FMS-3 & {$[0.1502,0.1836]$} & {$[0.0386,0.0578]$} & {$[0.0184,0.0257]$} & {$[0.0539,0.0746]$} & {$[0.0282,0.0297]$} & {$[0.0161,0.0250]$} \\
FMS-4 & {$[0.1168,0.1419]$} & {$[0.0337,0.0482]$} & {$[0.0147,0.0257]$} & {$[0.0539,0.0705]$} & {$[0.0178,0.0238]$} & {$[0.0196,0.0232]$} \\
A $^{+}$ & {$[0.0668,0.1002]$} & {$[0.0867,0.0964]$} & {$[0.0239,0.0367]$} & {$[0.0664,0.0829]$} & {$[0.0282,0.0297]$} & {$[0.0250,0.0321]$} \\
$\mathbf{A}^{-}$ & {$[0.1753,0.2003]$} & {$[0.0337,0.0482]$} & {$[0.0147,0.0257]$} & {$[0.0498,0.0705]$} & {$[0.0178,0.0238]$} & {$[0.0161,0.0250]$} \\
\hline
\end{tabular}

Table 3

Separation measures, relative closeness and ranking of each alternative

\begin{tabular}{lcccc}
\hline Alternatives & $\mathbf{S}_{\mathbf{i}}^{+}$ & $\mathbf{S}_{\mathbf{i}}^{+}$ & $\mathbf{R}_{\mathbf{i}}$ & Rank \\
\hline FMS-1 & 0.114581 & 0.081164 & 0.4146408 & $\mathbf{2}$ \\
FMS-2 & 0.050588 & 0.145158 & 0.7415641 & $\mathbf{1}$ \\
FMS-3 & 0.153494 & 0.042252 & 0.2158501 & $\mathbf{4}$ \\
FMS-4 & 0.134358 & 0.061388 & 0.3136095 & $\mathbf{3}$ \\
\hline
\end{tabular}

\subsection{Interval-valued EDAS}

The interval valued decision matrix was solved using interval valued EDAS. Interval valued average solution $\left[A_{j}^{l}, A_{j}^{u}\right]$ for the decision matrix was calculated, which was further used to calculate the value of interval valued PDA $\left[D_{i j}^{+1}, D_{i j}^{+u}\right]$ and interval valued NDA $\left[D_{i j}^{-1}, D_{i j}^{-u}\right]$, shown in Table 4. The weighted 
sum of interval valued PDA $\left[\mathrm{Q}_{\mathrm{i}}^{+1}, \mathrm{Q}_{\mathrm{i}}^{+\mathrm{u}}\right]$ and weighted sum of interval valued NDA $\left[\mathrm{Q}_{\mathrm{i}}^{-1}, \mathrm{Q}_{\mathrm{i}}^{-\mathrm{u}}\right]$ was calculated to find the value of normalised value of $\left[\mathrm{Q}_{\mathrm{i}}^{+1}, \mathrm{Q}_{\mathrm{i}}^{+\mathrm{u}}\right]$ and $\left[\mathrm{Q}_{\mathrm{i}}^{-1}, \mathrm{Q}_{\mathrm{i}}^{-\mathrm{u}}\right]$ i.e. $\left[\mathrm{S}_{\mathrm{i}}^{+1}, S_{\mathrm{i}}^{+\mathrm{u}}\right]$ and $\left[\mathrm{S}_{\mathrm{i}}^{-1}, S_{\mathrm{i}}^{-\mathrm{u}}\right]$. Based on which $\left[\mathrm{S}_{\mathrm{i}}^{+1}, S_{\mathrm{i}}^{+\mathrm{u}}\right]$ and $\left[\mathrm{S}_{\mathrm{i}}^{-1}, S_{\mathrm{i}}^{-\mathrm{u}}\right]$ the appraisal score $\mathrm{S}_{\mathrm{i}}$ for the alternatives was calculated, which was used to calculate the final ranking of alternatives. The values are shown in table- 5 .

Table 4

\begin{tabular}{|c|c|c|c|c|c|c|}
\hline \multicolumn{7}{|c|}{ Interval valued PDA $\left[D_{i j}^{+l}, D_{i j}^{+u}\right]$} \\
\hline & ADM & $\mathbf{Q}$ & $\mathbf{E}$ & C & $\mathbf{A}$ & $\mathbf{X}$ \\
\hline FMS-1 & {$[0,0]$} & {$[0.25,0.6731]$} & {$[0,0.7843]$} & {$[0,0.4127]$} & {$[0,0.2170]$} & {$[0,0.3364]$} \\
\hline FMS-2 & {$[0.1912,0.6324]$} & {$[0,0.4423]$} & {$[0,0.3137]$} & {$[0,0.2222]$} & {$[0,0.1550]$} & {$[0,0.4859]$} \\
\hline FMS-3 & {$[0,0.0441]$} & {$[0,0.0577]$} & {$[0,0.3137]$} & {$[0,0.2857]$} & {$[0.0775,0.3411]$} & {$[0,0.1869]$} \\
\hline FMS-4 & {$[0,0.2794]$} & {$[0,0]$} & {$[0,0.3137]$} & {$[0,0.2222]$} & {$[0,0.0930]$} & {$[0,0.1121]$} \\
\hline \multicolumn{7}{|c|}{ Interval valued $N D A\left[D_{i j}^{-l}, D_{i j}^{-u}\right]$} \\
\hline & ADM & Q & E & C & $\mathbf{A}$ & $\mathbf{X}$ \\
\hline FMS-1 & {$[0.1324,0.5147]$} & {$[0,0]$} & {$[0,0.1961]$} & {$[0,0.1270]$} & {$[0,0.3566]$} & {$[0,0.2430]$} \\
\hline FMS-2 & {$[0,0]$} & {$[0,0.2115]$} & {$[0,0.5098]$} & {$[0,0.3810]$} & {$[0,0.1705]$} & {$[0,0.0935]$} \\
\hline FMS-3 & {$[0,0.3971]$} & {$[0,0.5192]$} & {$[0,0.4314]$} & {$[0,0.3175]$} & {$[0,0]$} & {$[0,0.4673]$} \\
\hline FMS-4 & {$[0,0.1029]$} & $\begin{array}{c}{[0.0962} \\
0.5962] \\
\end{array}$ & {$[0,0.5882]$} & {$[0,0.3175]$} & {$[0,0.3566]$} & {$[0,0.3178]$} \\
\hline
\end{tabular}

Table 5

Appraisal score $\mathrm{S}_{\mathrm{i}}$ Based on $\left[\mathrm{S}_{\mathrm{i}}^{+1}, \mathrm{~S}_{\mathrm{i}}^{+\mathrm{u}}\right]$ and $\left[\mathrm{S}_{\mathrm{i}}^{-\mathrm{l}}, \mathrm{S}_{\mathrm{i}}^{-\mathrm{u}}\right]$

\begin{tabular}{cccccc}
\hline$\left[\mathrm{Q}_{\mathrm{i}}^{+1}, \mathrm{Q}_{\mathrm{i}}^{+\mathrm{u}}\right]$ & {$\left[\mathrm{Q}_{\mathrm{i}}^{-1}, \mathrm{Q}_{\mathrm{i}}^{-\mathrm{u}}\right]$} & {$\left[\mathrm{S}_{\mathrm{i}}^{+1}, \mathrm{~S}_{\mathrm{i}}^{+\mathrm{u}}\right]$} & {$\left[\mathrm{S}_{\mathrm{i}}^{-1}, \mathrm{~S}_{\mathrm{i}}^{-\mathrm{u}}\right]$} & $\mathrm{Si}$ & Rank \\
\hline$[0.0469,0.2955]$ & {$[0.0554,0.2941]$} & {$[0.1030,0.6494]$} & {$[0.2360,0.8560]$} & 0.461115 \\
{$[0.0801,0.4551]$} & {$[0,0.1643]$} & {$[0.1759,1]$} & {$[0.5733,1]$} & 0.687308 \\
{$[0.0053,0.1407]$} & {$[0,0.3849]$} & {$[0.0117,0.3092]$} & {$[0,1]$} & 0.330236 \\
{$[0,0.1943]$} & {$[0.0180,0.3012]$} & {$[0.0000,0.4271]$} & {$[0.2175,0.9532$} & 0.399425 \\
\hline
\end{tabular}

\subsection{Interval-valued CODAS}

The interval-valued CODAS was used to solve the interval valued decision matrix. It was normalised and interval valued weighted decision matrix was calculated. The interval valued negative-ideal solution was determined, which is shown in Table 6 . The relative assessment matrix was calculated with the help of Euclidean $\left(\mathrm{E}_{\mathrm{i}}\right)$ and Taxicab $\left(T_{\mathrm{i}}\right)$ distances of alternatives from the interval valued negative-ideal solution. Final assessment score and ranks of the alternative was calculated, which is shown in Table 7.

Table 6

Interval valued weighted decision matrix and interval valued negative-ideal solution

\begin{tabular}{ccccccc}
\hline & ADM & $\mathbf{Q}$ & $\mathbf{E}$ & $\mathbf{C}$ & $\mathbf{A}$ & $\mathbf{X}$ \\
\hline FMS-1 & {$[0.140,0.160]$} & {$[0.169,0.188]$} & {$[0.045,0.069]$} & {$[0.150,0.187]$} & {$[0.041,0.062]$} & {$[0.046,0.061]$} \\
FMS-2 & {$[0.279,0.419]$} & {$[0.113,0.159]$} & {$[0.031,0.048]$} & {$[0.112,0.159]$} & {$[0.052,0.058]$} & {$[0.054,0.069]$} \\
FMS-3 & {$[0.152,0.186]$} & {$[0.075,0.113]$} & {$[0.034,0.048]$} & {$[0.122,0.169]$} & {$[0.065,0.069]$} & {$[0.034,0.054]$} \\
FMS-4 & {$[0.197,0.239]$} & {$[0.066,0.094]$} & {$[0.028,0.048]$} & {$[0.122,0.159]$} & {$[0.041,0.055]$} & {$[0.042,0.050]$} \\
NS $_{\mathbf{j}}$ & {$[0.140,0.160]$} & {$[0.066,0.094]$} & {$[0.028,0.048]$} & {$[0.112,0.159]$} & {$[0.041,0.055]$} & {$[0.034,0.054]$} \\
\hline
\end{tabular}

Table 7

Relative assessment matrix and final assessment score

\begin{tabular}{lcccccc}
\hline & FMS-1 & FMS-2 & FMS-3 & FMS-4 & $\boldsymbol{H}_{\boldsymbol{i}}$ & \multicolumn{2}{c}{ Rank } \\
\hline FMS-1 & 0 & -0.1114 & 0.1076 & 0.0693 & 0.0655 & $\mathbf{2}$ \\
FMS-2 & 0.1805 & 0 & 0.3380 & 0.2895 & 0.8080 & $\mathbf{1}$ \\
FMS-3 & -0.0724 & -0.1340 & 0 & -0.0305 & -0.2369 & $\mathbf{4}$ \\
FMS-4 & -0.0486 & -0.1204 & 0.0317 & 0 & -0.1373 & $\mathbf{3}$ \\
\hline
\end{tabular}




\section{Discussion and conclusion}

The ranking obtained by various researchers using different MCDM methods were compared with the ranking obtained by three interval-valued MCDM method i.e. Interval-valued TOPSIS, interval-valued EDAS and interval-valued CODAS, which is shown in table-8. All three methods are distance-based approach i.e. interval-valued TOPSIS calculate the Euclidian distance from the negative ideal solution, interval-valued EDAS calculate distance from PDA and NDA, while interval-valued CODAS measure the Euclidian and taxicab distance from the negative-ideal solution. All the three methods gave exact same ranking which was similar to the rank obtained by MACBETH software. The ranks obtained by EDBA and Preference selection index method for FMS-1 and FMS-2 are same but the ranks for FMS-3 and FMS-4 are different. This difference in ranking justifies the effect of converting different interval data to same linguistic term and then converting it to crisp score for further solving it using MCDM methods.

Table 8

Comparison of ranking for FMS using various MCDM methods

\begin{tabular}{lcccccc}
\hline & $\begin{array}{c}\text { EDBA } \\
\text { Rao \& } \\
\text { Singh, } \\
2011)\end{array}$ & $\begin{array}{c}\text { Preference selec- } \\
\text { tion index method } \\
\text { (Maniya \& Bhatt, } \\
\text { 2011) }\end{array}$ & $\begin{array}{c}\text { MACBETH } \\
\text { (Karande \& } \\
\text { Chakraborty, } \\
2013)\end{array}$ & $\begin{array}{c}\text { Interval- } \\
\text { valued } \\
\text { TOPSIS }\end{array}$ & $\begin{array}{c}\text { Interval- } \\
\text { valued } \\
\text { EDAS }\end{array}$ & $\begin{array}{c}\text { Interval- } \\
\text { valued } \\
\text { CODAS }\end{array}$ \\
\hline FMS-1 & 2 & 2 & 2 & 2 & 2 & 2 \\
FMS-2 & 1 & 1 & 1 & 1 & 1 & 1 \\
FMS-3 & 3 & 3 & 4 & 4 & 4 & 4 \\
FMS-4 & 4 & 4 & 3 & 3 & 3 & 3 \\
\hline
\end{tabular}

Weightage of the criteria plays a key role in the final ranking of the alternatives. It can be seen that maximum weightage i.e. $41.88 \%$ was allotted to annual depreciation and maintenance costs, which made FMS-2 the best alternative, as FMS-2 have minimum ADM. The results obtained by some researchers is different from the current result because the interval-valued data was converted to fuzzy number which yielded different ranking. Concept of fuzzy is more appropriate in MCDM problem where data in decision matrix is completely vague. Interval-valued data are partial vague data and concepts of intervalvalue MCDM methods are more appropriate in solving those problem. These methods can effectively solve various problem which have interval data in the decision matrix. Thus, they can give more accurate result when compared to other methods.

\section{References}

Chen, F.D., Zhang, X., Kang, F., Fan, Z.P., \& Chen, X. (2010). A method for interval multiple attribute decision making with loss aversion. In Information Science and Management Engineering (ISME), 2010 International Conference of (Vol. 1, pp. 453-456).

Dymova, L., Sevastjanov, P. \& Tikhonenko, A. (2013). A direct interval extension of TOPSIS method. Expert Systems with Applications, 40, 4841-4847.

Hafezalkotob, A., \& Hafezalkotob, A. (2017). Interval MULTIMOORA method with target values of attributes based on interval distance and preference degree: biomaterials selection. Journal of Industrial Engineering International, 13(2), 181-198.

Hafezalkotob, A. \& Hafezalkotob, A. (2017). Interval target-based VIKOR method supported on interval distance and preference degree for machine selection. Engineering Applications of Artificial Intelligence, 57, 184-196.

Jahanshahloo, G. R., Khodabakhshi, M., Lotfi, F. H., \& Goudarzi, M. M. (2011). A cross-efficiency model based on super-efficiency for ranking units through the TOPSIS approach and its extension to the interval case. Mathematical and Computer Modelling, 53(9-10), 1946-1955. 
Jahanshahloo, G. R., Lotfi, F. H., \& Davoodi, A. R. (2009). Extension of TOPSIS for decision-making problems with interval data: Interval efficiency. Mathematical and Computer Modelling, 49(5-6), $1137-1142$.

Jahanshahloo, G. R., Lotfi, F. H., \& Izadikhah, M. (2006). An algorithmic method to extend TOPSIS for decision-making problems with interval data. Applied mathematics and computation, 175(2), 13751384.

Karande, P., \& Chakraborty, S. (2013). Evaluation and selection of flexible manufacturing systems using MACBETH method. International Journal of Services and Operations Management, 16(1), 123-144.

Keshavarz Ghorabaee, M., Zavadskas, E. K., Olfat, L., \& Turskis, Z. (2015). Multi-criteria inventory classification using a new method of evaluation based on distance from average solution (EDAS). Informatica, 26(3), 435-451..

Keshavarz Ghorabaee, M., Zavadskas, E. K., Turskis, Z., \& Antucheviciene, J. (2016). A new combiative distance-based assessment (CODAS) method for multi-criteria decision-making. Economic Computation \& Economic Cybernetics Studies \& Research, 50(3).

Kracka, M., \& Zavadskas, E. K. (2013). Panel building refurbishment elements effective selection by applying multiple-criteria methods. International Journal of Strategic Property Management, 17(2), 210-219.

Kulak, O., \& Kahraman, C. (2005). Multi-attribute comparison of advanced manufacturing systems using fuzzy vs. crisp axiomatic design approach. International Journal of Production Economics, 95(3), 415-424.

Maniya, K. D., \& Bhatt, M. G. (2011). The selection of flexible manufacturing system using preference selection index method. International Journal of Industrial and Systems Engineering, 9(3), 330-349.

Mathew, M., \& Sahu, S. (2018). Comparison of new multi-criteria decision making methods for material handling equipment selection. Management Science Letters, 8(3), 139-150.

Pan, J., Teklu, Y., Rahman, S., \& de Castro, A. (2000). An interval-based MADM approach to the identification of candidate alternatives in strategic resource planning. IEEE Transactions on Power Systems, 15(4), 1441-1446.

Rao, R. V., \& Parnichkun, M. (2009). Flexible manufacturing system selection using a combinatorial mathematics-based decision-making method. International Journal of Production Research, 47(24), 6981-6998.

Rao, R. V., \& Singh, D. (2011). Evaluating flexible manufacturing systems using Euclidean distancebased integrated approach. International Journal of Decision Sciences, Risk and Management, 3(12), 32-53.

Sayadi, M. K., Heydari, M., \& Shahanaghi, K. (2009). Extension of VIKOR method for decision making problem with interval numbers. Applied Mathematical Modelling, 33(5), 2257-2262.

Sayyadi, M., \& Makui, A. (2012). A new view to uncertainty in Electre III method by introducing interval numbers. Decision Science Letters, 1(1), 33-38.

Stanujkic, D., Magdalinovic, N., Milanovic, D., Magdalinovic, S., \& Popovic, G. (2014). An efficient and simple multiple criteria model for a grinding circuit selection based on MOORA method. Informatica, 25(1), 73-93.

Stanujkic, D., Zavadskas, E. K., Ghorabaee, M. K., \& Turskis, Z. (2017). An extension of the EDAS method based on the use of interval grey numbers. Studies in Informatics and Control, 26(1), 5-12.

Tsaur, R. C. (2011). Decision risk analysis for an interval TOPSIS method. Applied Mathematics and Computation, 218(8), 4295-4304.

Ye, F., \& Li, Y. N. (2009). Group multi-attribute decision model to partner selection in the formation of virtual enterprise under incomplete information. Expert Systems with Applications, 36(5), 9350-9357. 
(C) 2019 by the authors; licensee Growing Science, Canada. This is an open access article distributed under the terms and conditions of the Creative Commons Attribution (CC-BY) license (http://creativecommons.org/licenses/by/4.0/). 